\title{
PENGARUH KUALITAS LAYANAN, KEPERCAYAAN, DAN CITRA PERUSAHAAN TERHADAP KEPUASAN NASABAH PENGGUNA BRANCHLESS BANKING (STUDI KASUS BANK CIMB NIAGA KANTOR CABANG PINANGSIA TANGERANG)
}

\author{
Dewi Wahyunie \\ Program Studi Magister Manajemen Universitas Tarumanagara \\ mail.dewiyanggg3@gmail.com
}

Masuk : 07-12-2020, revisi : 16-12-2020, diterima untuk diterbitkan : 17-12-2020

\begin{abstract}
The purpose of this research is to test, analyzing and find out the effect of service quality, trust, and corporate image on the customer satisfaction of Branchless Banking CIMB Niaga use. The sampling technique used in this research is nonprobability sampling by accidental sampling using a quantitative approach by distributing questionnaires to 100 respondents of customers CIMB Niaga Bank. The data analysis method used in this research is multiple regression analysis. For operational variables using the Likert scale method of validity used a computer measuring instrument that is SPSS 26.0. The results showed that all independent variables have a simultaneous effect on the customer satisfaction of Branchless Banking CIMB Niaga usage positively and also have a positive effect on the customer satisfaction of Branchless Banking CIMB Niaga usage. Thus, service quality, trust, and corporate image have a positive effect and significance on the customer satisfaction of Branchless Banking CIMB Niaga usage.
\end{abstract}

Keywords: Service Quality, Trust, Corporate Image, Customer Satisfaction, Branchless Banking

Abstrak: Penelitian ini bertujuan untuk menguji, menganalisis serta mengetahui pengaruh langsung kualitas layanan, kepercayaan dan citra perusahaan terhadap kepuasan nasabah pengguna Branchless Banking CIMB Niaga. Teknik pengambilan sampel menggunakan nonprobability sampling dengan cara accidental sampling, pendekatan kuantitatif dilakukan dengan cara menyebarkan kuesioner kepada 100 responden nasabah Bank CIMB Niaga Metode analisis data yang digunakan adalah analisis regresi linear berganda dan untuk variabel operasional menggunakan skala Likert dengan bantuan SPSS 26.0. Hasil penelitian menunjukkan bahwa semua variable independent secara bersama-sama berpengaruh positif dan signifikan secara individual terhadap kepuasan nasabah pengguna Branchless Banking.

Kata Kunci: Kualitas Layanan, Kepercayaan, Citra Perusahaan, Kepuasan Nasabah, Branchless Banking

\section{PENDAHULUAN}

Perkembangan teknologi informasi menyebabkan dampak yang signifikan terhadap kehidupan manusia. Perkembangan ini hampir menyentuh seluruh sektor industri yang bergerak dalam bidang usaha barang ataupun jasa, maka dari itu banyak perusahaan dituntut untuk selalu berpikir kreatif dan inovatif agar tetap dapat bertahan dalam persaingan usaha. Pembentukan kualitas layanan, kepercayaan, citra perusahaan serta kepuasan nasabah yang tepat dapat menjadi cara efektif untuk memberikan dampak langsung terhadap peningkatan keunggulan bersaing suatu perusahaan terhadap perusahan kompetitor. Tujuan dari penelitian ini diharapkan dapat menjelaskan pengaruh kualitas layanan, kepercayaan, dan citra perusahaan terhadap pengguna Branchless Banking kepada pihak perusahaan, dalam hal ini Bank CIMB Niaga. Kualitas layanan diartikan sebagai tingkat kepuasan konsumen, sedangkan tingkat kepuasan konsumen didaptkan dari perbandingan atas jenis pekayanan yang nyata 
diterima oleh konsumen dengan jenis pelayanan yang diharapkan/sesuai dengan harapan. Kualitas juga bisa diartikan sebagai suatu kondisi dinamis yang berpengaruh dengan produk jasa manusia, proses dan lingkungan yang memenuhi atau melebihi harapan (Tjiptono, 2001, p. 102). Selain itu, kepuasan nasabah juga tidak kalah penting bagi suatu perusahaan dalam bidang jasa perbankan karena dengan adanya kepuasan nasabah akan mempertahankan citra perusahaan di masyarakat sehingga pelayanan yang baik dan bermutu perlu ditingkatkan. Selain itu peranan kualitas layanan yang baik akan berkontribusi mendapatkan pendapatan secara langsung maupun tidak langsung untuk mendukung eksistensi suatu perusahaan.

Tantangan usaha atau bisnis yang berfokus terhadap kualitas layanan, kepercayaan, citra perusahaan serta dampaknya terhadap kepuasan nasabah pada era teknologi informasi seperti saat ini terjadi hampir di semua sektor industri, baik dalam bidang kesehatan, pendidikan, transportasi, dan lain sebagainya. Tantangan ini juga menyentuh sektor perbankan. Bank dituntut melakukan terobosan terhadap kemajuan teknologi dalam rangka menciptakan kepuasan nasabah. Bank CIMB Niaga merupakan salah satu bank swasta terbesar di Indonesia yang mempunyai cabang di setiap kota dan unit-unit yang hampir di setiap kecamatan, menjadi salah satu bank yang dijadikan nasabah untuk melakukan simpan pinjam maupun transkasi lainnya. Bank CIMB Niaga menyediakan berbagai macam layanan perbankan elektronik seperti mesin ATM dan CDM, Octo Mobile, Octo Clicks, Rekening Ponsel, Bizchannel, dan Digital Lounge. Semua fasilitas dan fitur elektronik tersebut dinamakan Branchless Banking. Hampir semua bank yang ada di Indonesia saat ini, baik bank milik negara ataupun bank swasta berkompetisi untuk menciptakan teknologi terbaik dan teraman agar tidak tertinggal oleh bank pesaing, yang tujuan akhirnya adalah untuk menarik minat nasabah aktif dan nasabah baru untuk menggunakan produk layanan mereka.

\section{TELAAH PUSTAKA Branchless Banking}

Branchless Banking adalah jaringan distribusi yang digunakan untuk memberi layanan finansial di luar kantor-kantor cabang bank melalui teknologi dan jaringan alternatif dengan biaya efektif dan efisien, serta dalam kondisi yang aman dan nyaman. Branchless Banking dapat didefinisikan sebagai "a distribution channel strategy used for delivering financial services without relying on Bank branches" atau dengan kata lain merupakan inovasi perbankan dimana bank melakukan pemberian layanan keuangan di luar kantor cabang seperti memberikan fasilitas mesin ATM ataupun aplikasi dan fitur-fitur yang dapat digunakan nasabah untuk bertransaksi di mana saja.

\section{Kualitas Layanan}

Kualitas bisa disebut sebagai kondisi dimana hal-hal yang berhubungan dengan suatu produk, jasa, manusia, proses, dan lingkungan yang memenuhi atau melebihi harapan (Goetsch \& Davis, 1994; Tjiptono, 2000, p. 51). Selain itu, kualitas pelayanan adalah suatu cara kerja perusahaan yang berusaha mengadakan perbaikan mutu secara terus menerus terhadap proses, produk dan pelayanan yang dihasilkan (Alma, 2007, p. 286).

\section{Kepercayaan}

Kepercayaan merupakan hal penting dalam mengembangkan hubungan jangka panjang antar organisasi. Suatu organisasi harus mampu mengenali faktor-faktor yang dapat membentuk kepercayaan agar dapat menciptakan, mengatur, memelihara, menyokong dan mempertinggi tingkat hubungan dengan pelanggan. Kepercayaan juga bisa dikatakan sebagai suatu proses menghitung (calculative process) antara biaya yang dikeluarkan dengan hasil yang diperoleh (Aydin \& Ozer, 2005). Pelayanan baik yang diterima sekarang akan berlanjut untuk kedepannya, sehingga service quality berpengaruh positif terhadap trust. Sedangkan menurut teori Trust-Commitment (Morgan \& Hunt, 1994), trust adalah satu variabel kunci untuk memelihara suatu hubungan jangka panjang termasuk pada sebuah merek. 


\section{Citra Perusahaan}

Citra perusahaan adalah sebuah proses (Aydin \& Ozer, 2005; MacInnis \& Price, 1987). Berawal dari ide, perasaan dan pengalaman mengkonsumsi perusahaan yang didapat dari ingatan dan diubah ke dalam citra mental (batin). Citra perusahaan menentukan identitas dari perusahaan tersebut. Setiap perusahaan memiliki kepribadian yang dapat didefinisikan sebagai seperangkat karakteristik, perilaku dan intelektual yang berfungsi untuk membedakan perusahaan yang satu dengan perusahaan yang lainnya. perusahaan yang direfleksikan dalam asosiai yang terdapat dalam memori konsumen. Seperti dicatat di atas citra perusahaan berasal dari pengalaman mengkonsumsi konsumen dimana service quality adalah fungsi dari pengalaman mengkonsumsi ini sehingga service quality secara langsung berpengaruh pada corporate image (Aydin \& Ozer, 2005).

\section{Kepuasan Nasabah}

Kepuasan pelanggan adalah rasa senang atau kecewa seseorang yang berasal dari perbandingan antara kesan terhadap kinerja atau hasil suatu produk dengan harapannya. Kepuasan pelanggan terhadap perusahaan tinbul karena adanya pengalaman saat bertransaksi dengan perusahaan segingga memberikan reaksi positif dari pelanggan dan memberikan dampak besar pada kelangsungan usaha atau hubungan jangka Panjang antara pelanggan dengan perusahaan (Kurniasari \& Ernawati, 2012). Bisa dikatakan bahwa pelanggan mencapai rasa puas atau kepuasan apabila pelanggan merasakan hasil yang sesuai dengan harapan atau ekspetasi.

\section{Hipotesis Konseptual}

Pada dasarnya hipotesis merupakan pernyataan tentang sesuatu yang untuk sementara waktu dianggap benar, bisa juga diartikan yang akan diteliti sebagai jawaban sementara dari suatu masalah (Supranto, 2012). Berdasarkan pernyataan tersebut, maka dirumuskan bahwa hipotesis penelitian ini sebagai berikut :

H1 = Kualitas layanan mempengaruhi kepuasan nasabah pengguna Branchless Banking CIMB Niaga

$\mathrm{H} 2$ = Kepercayaan mempengaruhi kepuasan nasabah pengguna Branchless Banking CIMB Niaga

H3 = Citra perusahaan mempengaruhi kepuasan nasabah pengguna Branchless Banking CIMB Niaga

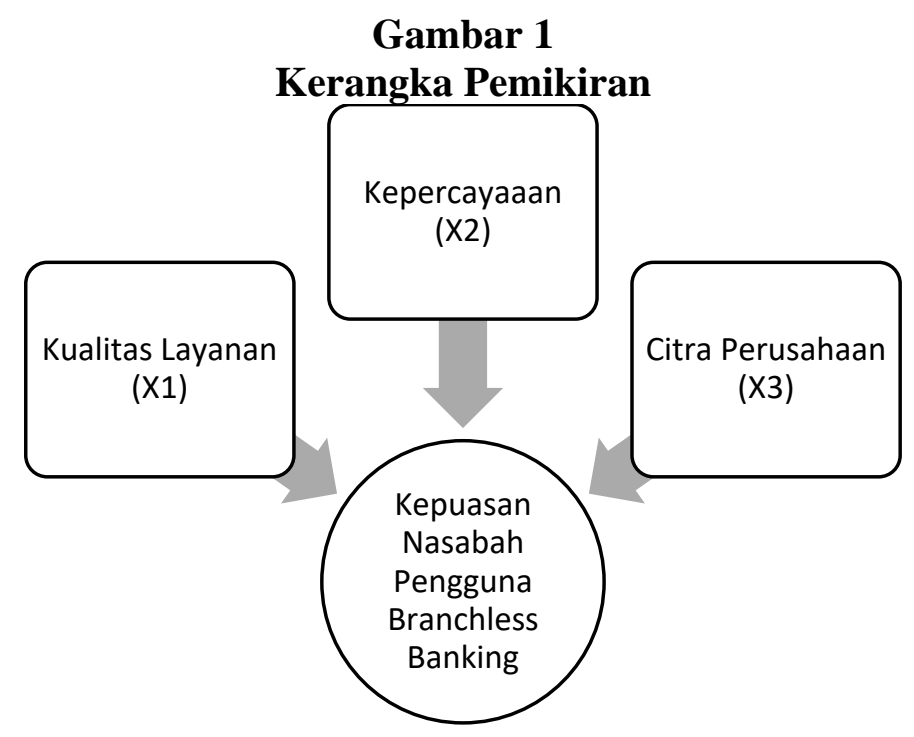

\section{METODOLOGI PENELITIAN}

Metode yang digunakan dalam penelitian ini adalah metode kuantitatif, yaitu pengukuran variabel-variabel penelitian dalam bentuk angka dan melakukan analisis dalam bentuk statistik. populasi dalam penelitian ini adalah nasabah pengguna Branchless Banking di Bank CIMB 
Niaga Kantor Cabang Pinangsia Tangerang, dengan sampel penelitian adalah 100 responden. Metode pengambilan sampel menggunakan nonprobability sampling dengan accidental sampling. Berdasarkan data yang didapat, mayoritas karakteristik responden pada penelitian adalah wanita sebesar 62\%, berusia 21-30 tahun (78\%), pekerjaan karyawan swasta $74 \%$, dengan lama pengguna Branchless Banking $<1$ tahun (54\%) dengan rata-rata penggunaan 5 s/d 10 kali dalam sebulan (46\%).

Pada penelitian ini, variabel kualitas layanan, kepercayaan, dan citra perusahaan merupakan variabel independent sedangkan kepuasan nasabah merupakan variabel dependent. Dalam pengukuran variabel, metode yang digunakan adalah Skala Likert. Metode analisa data menggunakan analisis regresi linear berganda. Sedangkan, untuk uji asumsi seperti uji normalitas, uji multikolinieritas dan uji heterokedastisitas telah dilakukan sebelumnya dan hasilnya menunjukkan semua uji asumsi sudah terpenuhi. Pengujian dalam penelitian ini menggunakan prpgram SPSS 26.0. Taraf signifikansi yang digunakan dalam penelitian ini adalah 0,05 .

Tabel 1

Variabel dan Pengukuran

\begin{tabular}{ccc}
\hline Variabel & Jumlah Item & Sumber \\
\hline Independent Variable & & \\
1. Kualitas Layanan & 5 & Wu et al., (2012) \\
2. Kepercayaan & 6 & Kotler dan Keller (2007) \\
3. Citra Perusahaan & 4 & Harrison (2005) \\
Dependent Variable & & \\
1. Kepuasan Nasabah & 5 & Tjiptono (2000) \\
\hline
\end{tabular}

\section{ANALISA DAN PEMBAHASAN}

Berdasarkan hasil pengujian hipotesis maka dapat disimpulkan bahwa variabel kualitas layanan, kepercayaan dan citra perusahaan secara simultan berpengaruh positif dan signifikan terhadap kepuasan nasabah pengguna Branchless Banking CIMB Niaga karena adanya kualitas layanan, kepercayaan dan citra perusahaan yang baik. Hipotesis $\mathrm{H} 1$ sesuai dengan penelitian Louisrianda \& Tabrani (2017) yang mengemukakan bahwa kualitas layanan menunjukan hasil yang positif dan signifikan mempengaruhi kepuasan nasabah. Semakin bagus kualitas pelayanan maka semakin kuat juga kepuasan pelanggan. Selanjutnya Hipotesis H2 mengemukakan bahwa kepercayaan secara positif dan signifikan mempengaruhi kepuasan nasabah. Ini menunjukkan bahwa semakin nyata kepercayaan yang dirasakan nasabah maka semakin meningkat juga kepuasan nasabah tersebut. Kemudian untuk Hipotesis H3 juga menunjukan hasil yang positif dan signifikan mempengaruhi kepuasan nasabah. Semakin baik citra perusahaan maka akan semakin kuat juga kepuasan pelanggan. Selanjutnya untuk menunjukkan hasil dari pengujian hipotesis dari penelitian ini dapat dilihat pada Tabel 2.

Dengan demikian maka seluruh hipotesis penelitian ini terbukti dengan adanya data secara empiris. Kepuasan nasabah pengguna Branchless Banking CIMB Niaga dapat diprediksi oleh kualitas layanan, kepercayaan, dan citra perusahaan. Maka dapat dilihat bahwa kepuasan nasabah pengguna Branchless Banking CIMB Niaga dapat dipengaruhi oleh kualitas Bank CIMB Niaga sebagai bank swasta, kualitas layanan yang baik, berbagai macam fitur yang disediakan Branchless Banking yang dapat membantu transaksi perbankan nasabah. Begitu juga kepercayaan dan citra perusahaan yang dirasakan baik memiliki tanggung jawab sosial yang besar mempengaruhi keputusan nasabah dalam menggunakan produk jasa perbankan. Dalam hal kepuasan, dikategorikan puas, ini dibuktikan di lapangan bahwa jarangnya keluhan atas aplikasi dan fitur yang disediakan Branchless Banking CIMB Niaga. 


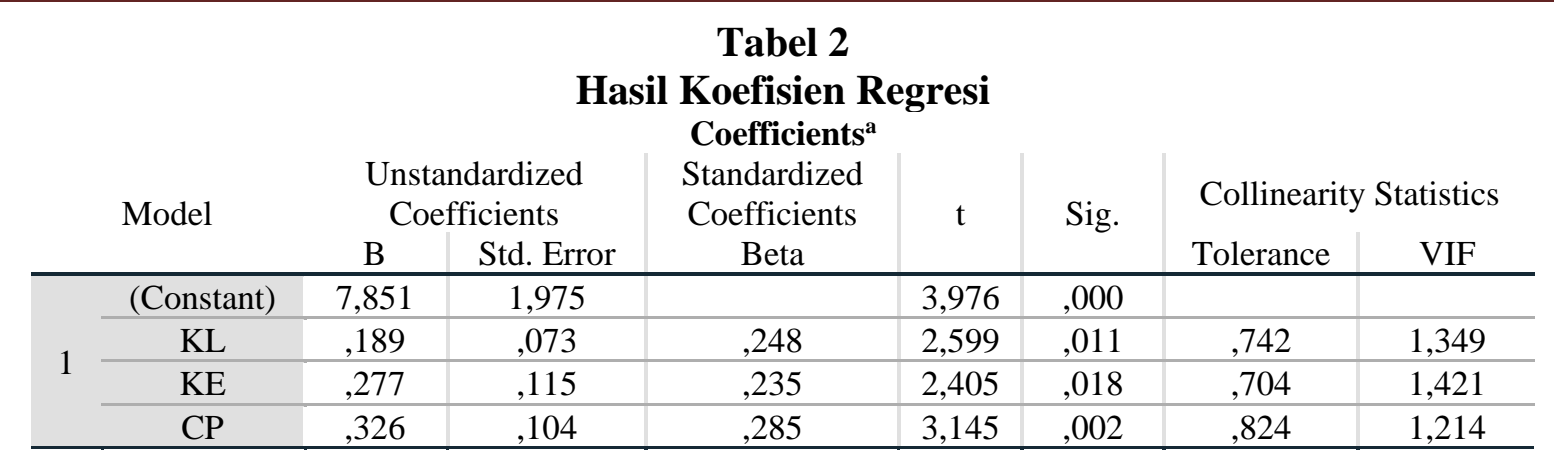

a. Dependent Variable: Kepuasan Nasabah (Y)

\section{KESIMPULAN DAN SARAN Kesimpulan}

Penelitian ini memperoleh hasil hasil bahwa variabel kualitas layanan, kepercayaan dan citra perusahaan secara simultan berpengaruh positif dan signifikan terhadap kepuasan nasabah pengguna Branchless Banking CIMB Niaga. Variabel kualitas layanan, kepercayaan, dan citra perusahaan juga secara parsial berpengaruh positif dan signifikan terhadap kepuasan nasabah pengguna Branchless Banking CIMB Niaga. Dari ketiga variabel bebas dalam penelitian ini, variabel citra perusahaan merupakan variabel yang paling dominan berpengaruh signifikan terhadap kepuasan nasabah pengguna Branchless Banking CIMB Niaga, dilihat dari nilai standardized coefficients beta yaitu sebesar 0,285.

\section{Saran}

Dalam penelitian ini tanggapan responden terhadap citra perusahaan merupakan kategori yang paling tinggi yang mempengaruhi kepuasan nasabah pengguna Branchless Banking CIMB Niaga dibandingkan dengan variabel lain, maka dari itu disarankan Bank CIMB Niaga KC Pinangsia Tangerang hendaknya selalu menjaga citra baik tersebut di mata masyarakat luas khususnya di mata nasabah. Bank CIMB Niaga juga disarankan untuk terus berupaya dalam mengembangkan kualitas layanan dan kepercayaan untuk meningkatkan kepuasan nasabah yang menggunakan fasilitas Branchless Banking CIMB Niaga dan menjadikannya semakin meningkat. Dalam hal kepercayaan, variabel ini mendapatkan nilai paling rendah dari ketiga variabel yang mempengaruhi kepuasan nasabah pengguna Branchless Banking CIMB Niaga. Diharapkan Bank CIMB dapat memberikan rasa aman dan nyaman kepada nasabah agar timbul kepercayaan nasabah terhadap Bank CIMB Niaga.

\section{DAFTAR PUSTAKA}

Alma, B. (2007). Manajemen pemasaran dan pemasaran jasa. Alfabeta CV.

Aydin, S., \& Ozer, G. (2005). National customer satisfaction indices: An implementation in the Turkish mobile telephone market. Marketing Intelligence and Planning, 23(5), 486504. https://doi.org/10.1108/02634500510612654

Goetsch, D. L., \& Davis, S. (1994). Introduction to total quality: Quality, productivity, competitiveness. Macmillian College Publishing Co.

Harrison, S. (2005). Public relations: An introduction. Thomson Learning.

Kotler, P., \& Keller, K. L. (2007). Manajemen pemasaran (12th ed.). PT Indeks Kelompok Gramedia.

Kurniasari, N., \& Ernawati, N. (2012). Pengaruh kepuasan pelanggan, kepercayaan, dan harga terhadap loyalitas pelanggan Laundry Kencling Semarang. Jurnal Mahasiswa QMAN, 1(3), 57-68.

Louisrianda, R., \& Tabrani, M. (2017). Pengaruh kualitas pelayanan, kepercayaan, citra perusahaan terhadap loyalitas merek dengan kepuasan pelanggan sebagai variabel mediasi pada maskapai Garuda Indonesia. Jurnal Ilmiah Mahasiswa Ekonomi Manajemen, 2(3), 154-177. https://doi.org/10.24815/jimen.v2i3.3540 
MacInnis, D. J., \& Price, L. L. (1987). The role of imagery in information processing: Review and extensions. Journal of Consumer Research, 13(4), 473-491. https://doi.org/10.1086/209082

Morgan, R. M., \& Hunt, S. D. (1994). The commitment-trust theory of relationship marketing. Journal of Marketing, 58(3), 20. https://doi.org/10.2307/1252308

Supranto, J. (2012). Metode riset aplikasinya dalam pemasaran. Rineka Cipta. Tjiptono, F. (2000). Perspektif manajemen dan pemasaran kontemporer. Andi. Tjiptono, F. (2001). Strategi pemasaran (5th ed.). Andi.

Wu, Y. L., Tao, Y. H., \& Yang, P. C. (2012). Learning from the past and present: Measuring Internet banking service quality. Service Industries Journal, 32(3), 477-497. https://doi.org/10.1080/02642069.2010.529434 